\title{
Organizações sociais, instituições federais de ensino superior e autonomia universitária
}

\section{Introdução}

O projeto de reforma do Estado proposto pelo atual governo, consubstanciado no Plano Diretor da Reforma do Aparelho do Estado, tem levantado debates tanto dentro do governo quanto na sociedade. Tal projeto se baseia num diagnóstico da administração pública que aponta como um dos seus principais problemas a rigidez decorrente da aplicação generalizada de normas burocráticas mesmo nos setores onde estas não são consideradas necessárias. Como solução, apresenta um modelo de Estado cujos setores de atuação são diferenciados, segundo seus fins, e associados a várias formas de propriedade, administração e vínculo com o Estado.

Dentro desse projeto destaca-se a idéia de Organizações Sociais (OS), que representariam um novo padrão de prestação de serviços sociais pelo Estado. Estas organizações seriam entidades privadas sem fins lucrativos que receberiam subvenção do governo federal para prestarem serviços de relevante interesse público. Tais entidades, apesar de serem organizadas segundo o direito privado, teriam um forte componente público, à medida que seriam dirigidas por um conselho cuja maioria dos membros seria indicada pelo poder público ou pela sociedade civil. A instituição seria avaliada através do controle de resultados, basicamente, verificando-se se os objetivos estabelecidos num contrato de gestão foram atingidos ou não.

Um dos alvos principais desse projeto são as Instituições Federais de Ensino Superior - IFES que poderiam adquirir maior flexibilidade administrativa se transformando em OS. Como estas movimentam um volume significativo de recursos, mais de 5 bilhões de reais por ano, conforme

Especialista em análise política pela Universidade Federal de Minas Gerais — UFMG 
aponta a Tabela 1, o MARE espera que a melhoria na sua gestão leve a uma significativa economia destes recursos ou a uma expansão na quantidade/qualidade dos serviços prestados.

No entanto, logo após a divulgação do Plano Diretor da Reforma do Aparelho do Estado e da concepção das OS, as IFES manifestaramse contra a proposta e aceleraram o trabalho de elaboração de uma proposta de autonomia universitária alternativa ao projeto de OS. O próprio Ministério da Educação e do Desporto - MEC aceitou a posição das IFES e vem trabalhando no sentido de criar uma legislação que regulamente a autonomia universitária estabelecida pela Constituição de 1988.

Tabela 1: Instituições Federais de Ensino Superior — IFES

Despesas custeadas pelo MEC

\begin{tabular}{lc}
\hline $\begin{array}{l}\text { Itens } \\
\text { da despesa }\end{array}$ & $\begin{array}{l}\text { Empenhado em 1995- } \\
\text { (em R\$ milhões) }\end{array}$ \\
\hline & $3.210,90$ \\
1. Pessoal ativo & 250,30 \\
2. Benefícios de serv. e res. médica & 300,90 \\
3. OCC com recursos do Tesouro & $3.726,10$ \\
4. Despesa total ativa (1+2+3) & $1.222,60$ \\
5. Inativos e pensionistas & 236,20 \\
6. Precatórios & $5.220,90$ \\
7. Despesa total das IFES (4+5+6) & \\
\hline
\end{tabular}

Fonte: MEC, 1996, p.14

Partindo dessas considerações, este trabalho se propõe a comparar a proposta das OS com a proposta do MEC de autonomia das IFES, apontando semelhanças e divergências, e elaborar algumas considerações sobre a viabilidade de ambas as propostas, considerando a situação atual dessas instituições.

\section{A reforma do aparelho do Estado e o projeto de Organizações Sociais}

\subsection{Breve histórico}

O projeto de Organizações Sociais foi elaborado pelo MARE a partir do diagnóstico apresentado no Plano Diretor da Reforma do Aparelho do Estado, que aponta a reforma do Estado como uma necessidade de que se coloca como reflexo da globalização da economia e da crise do Estado. 
A crise do Estado se manifesta através das crises fiscal e da do modo de intervenção econômica e social e pela crise do aparelho do Estado. Para compreender o contexto em que surge essa crise e seu reflexo sobre a administração pública, é conveniente que se faça um breve histórico da evolução da administração pública brasileira.

A administração burocrática começou a ser implantada no País com a criação do Dasp em 1936. Curiosamente, logo em seguida foi criada a primeira autarquia, representando a primeira percepção de que algumas atividades exercidas pelo Estado deveriam ser executadas de forma autônoma e com maior flexibilidade. Até 1967, o modelo burocrático de administração foi lentamente avançando no setor público, ao mesmo tempo em que eram criadas autarquias, quando se queria maior autonomia para determinado órgão ou atividade. À medida que o papel do Estado no desenvolvimento econômico foi aumentando, foram se fazendo necessárias novas formas de administração. Estas surgiram através de dois processos: da ampliação da administração indireta com a criação de autarquias, que possibilitavam maior autonomia administrativa e; na direta, da superposição de novas estruturas das já existentes, mantendo estas últimas intactas e gerando um crescimento "por camadas".

O primeiro processo foi utilizado na reforma administrativa de 1967 , quando o decreto-lei no 200 reestruturou a administração pública brasileira. Manteve-se o núcleo burocrático existente, mas privilegiou-se a administração indireta através da possibilidade de criação de autarquias, fundações, empresas públicas e sociedades de economia mista, que possuíam grande flexibilidade na gerência de seus recursos. Com esse setor indireto com elevada flexibilidade, surge a primeira idéia de um modelo de administração gerencial mais vinculado à obtenção de resultados do que a controles formais. Dentro dessa perspectiva, a reforma de 1967 privilegiou o planejamento, a racionalidade administrativa e o orçamento-programa como elementos de modernização do aparelho do Estado.

No entanto, o decreto-lei no 200 teve conseqüências indesejáveis. Em primeiro lugar, possibilitou a sobrevivência do patrimonialismo à medida que permitiu a contratação de funcionários na administração indireta sem a exigência de concursos ou processos seletivos públicos, facilitando assim a nomeação por critérios políticos. A falta de controle sobre a administração indireta, decorrente da não-institucionalização de instrumentos de controle por parte dos órgãos da administração direta, também contribuiu para que as autonomias concedidas dessem origem aos desmandos e à apropriação privada das instituições públicas. Por fim, a administração indireta com seu grande grau de autonomia se mostrou muito mais atraente em termos operacionais e políticos do que a rígida, lenta e ineficiente burocracia da administração direta. Como conseqüência, houve um grande 
estímulo à proliferação de autarquias e fundações e um "abandono" dos órgãos centrais do governo, ocasionando sua deterioração, dado que seus quadros não foram repostos e/ou qualificados e o desenvolvimento de carreiras de administradores foi abandonado.

A crise dos anos 80 e a redemocratização recolocaram em debate a estrutura do Estado. Como resultado desse debate, o Congresso Constituinte incorporou à nova constituição dispositivos que levaram a administração pública a retroceder na direção de um rígido modelo de administração burocrática.

Reagindo ao patrimonialismo e clientelismo existentes na administração indireta, tido como conseqüência da autonomia dos órgãos desse nível da administração, os constituintes enquadraram essa esfera da administração pública num modelo burocrático tradicional, retirando quase toda a sua flexibilidade e tornando-a indistinta, para efeitos práticos, da administração direta. Ignorou-se que a descentralização e a flexibilidade eram elementos centrais para que o Estado agisse eficientemente na prestação de serviços sociais. Na análise de Bresser Pereira (1996, p.15-16), a resposta do Congresso Constituinte se baseou na identificação equivocada entre a crise do Estado e, em parte, o processo de descentralização adotado pelo regime militar; na aliança política entre as forças democráticas e as forças conservadoras/patrimonialistas e no ressentimento da burocracia da administração direta que procurou se fortalecer através de um processo de centralização e de reafirmação do modelo burocrático. Houve também uma presença marcante de grupos corporativos do setor público no processo constituinte, resultando na inclusão dispositivos extremamente favoráveis aos servidores no texto final da Constituição.

As conseqüências desse "retrocesso burocrático" afetaram fortemente o setor público, notadamente no que se refere ao custo operativo da administração indireta (FERRAREZI et. al., 1996, p. 24), que apresentou significativo aumento. As vantagens dos servidores impactaram fortemente a despesa com pessoal, especialmente o gasto com aposentadorias e pensões. Estes dois fatores agravaram a crise fiscal, já acentuada pelo baixo nível da atividade econômica observada na primeira metade da década de 90. Sob o aspecto administrativo, a adoção do modelo burocrático para a administração indireta teve como conseqüência o incremento na ineficiência alocativa. A instituição de um rígido controle de processos em lugar do controle por resultados exacerbou a morosidade da administração. Dificuldades na contratação de pessoal, na execução das compras e no manejo dos recursos orçamentários também passaram a caracterizar a administração indireta. Todos esses elementos não foram acompanhados de uma melhoria qualitativa ou quantitativa na prestação dos serviços públicos, objetivo declarado dos constituintes, contribuindo, ao contrário, para dificultar ainda mais o atendimento das demandas da população. 
Dado esse diagnóstico, o Plano Diretor da Reforma do Aparelho do Estado apresenta como proposta a identificação de setores de atividades do Estado, com diferentes formas de propriedade e diferentes papéis que o Estado deveria exercer em cada uma deles. Esses setores seriam:

1) Núcleo estratégico do Estado

2) Atividades exclusivas do Estado

3) Serviços não-exclusivos ou competitivos e

4) Produção de bens e serviços para o mercado

No Núcleo estratégico, concentrar-se-iam as atividades de tomada de decisões e formulação de políticas. Este setor se manteria basicamente como é organizado atualmente.

No setor de atividades exclusivas, estariam as atividades cujo desempenho exige a presença do poder de Estado, como, por exemplo, as atividades de arrecadação, fiscalização, emprego da força policial, previdência básica, regulamentações diversas, etc. Nesse setor haveria "Agências Executivas" - AE que também seriam organizações estatais, mas que gozariam de autonomia administrativa no marco de um modelo de administração gerencial.

No setor de produção de bens e serviços para o mercado, o plano diretor advoga, em princípio, a privatização das empresas existentes. Caso seja conveniente a manutenção de algumas empresas em poder do Estado, estas deveriam ser organizadas e administradas segundo a ótica privada.

O setor de serviços não-exclusivos ou competitivos caracterizarse-ia pela prestação de serviços sociais, que são oferecidos pelo Estado por proporcionarem economias externas ou por não serem adequadamente remunerados através do mercado. Essa última característica, no entanto, não impede que o setor privado participe subsidiariamente do fornecimento de serviços desse tipo. Os serviços sociais estariam relacionados às áreas de saúde, educação, pesquisa científica e tecnológica, promoção cultural, etc., atualmente mantidos pelo poder público através de fundações e autarquias. O plano diretor aponta que esse setor deveria se organizar através de "Organizações Sociais" — OS.

\subsection{As Organizações Sociais}

As OS seriam entidades públicas não-estatais, ou seja, entidades regidas pelo direito privado com o objetivo de exercer uma atividade de interesse público. Tratar-se-ia de organizações não-lucrativas que receberiam uma subvenção do Estado enquanto desenvolvessem atividades de caráter público. Entre essas atividades encontram-se a prestação de serviços de saúde, educação, cultura, desenvolvimento científico e tecnológico entre outros. Essas instituições permaneceriam ligadas ao Estado à medida que este daria suporte ao seu funcionamento e participaria da definição de seus objetivos e metas. 
Seguindo o diagnóstico de que um dos principais problemas da administração pública seria a ausência de flexibilidade, a idéia de OS incorpora a noção de que a administração dos serviços prestados à população deve ter alto grau de autonomia. Esta seria garantida através de ampla liberdade administrativa, tanto com relação ao pessoal quanto com relação às compras, orçamentos, finanças, etc.

Essa flexibilidade possibilitaria a adoção de novos critérios de avaliação do êxito administrativo, que não os de correção e adequação às normas além da eficácia das decisões, que caracterizam a administração direta. As OS seriam avaliadas, segundo sua capacidade de prestar serviços à população, com agilidade, qualidade e eficiência, ao menor custo possível, dadas as circunstâncias.

A garantia de que o interesse público estaria presente no desenvolvimento das atividades da OS e de que estas não utilizariam a liberdade administrativa para a consecução de interesses divergentes dos interesses da sociedade seria dada por duas formas de controle. A primeira seria a obrigatoriedade de criação de um conselho de administração, ou conselho curador, da OS, em cuja composição estaria garantida a predominância de membros indicados pelo governo ou por entidades representativas da sociedade civil. No anteprojeto de lei que cria as OS, o MARE define a composição desses conselhos da seguinte forma:

1) $30 \%$ de representantes do Poder Público, na qualidade de membros natos;

2) $30 \%$ de membros indicados pelas entidades representativas da sociedade civil, na qualidade de membros natos;

3) $10 \%$ de membros indicados ou eleitos na forma estabelecida pelo Estatuto;

4) $30 \%$ de membros eleitos, pelos demais integrantes do conselho, dentre pessoas de notória capacidade profissional e reconhecida idoneidade moral.

A segunda forma de controle seria através do instrumento do contrato de gestão. Este contrato é um acordo realizado entre o governo e uma OS ou AE, para o desenvolvimento de um programa de fortalecimento institucional e de modernização da gestão, com vista atingir melhores resultados que objetivem uma superior qualidade do produto ou serviço prestado ao cidadão (Projeto Organizações Sociais, 1996). Neste trecho pode-se identificar o objetivo geral desse instrumento, que seria possibilitar uma gestão mais eficiente e que gerasse serviços de melhor qualidade. Esse objetivo geral seria alcançado através de um acordo entre as partes sobre objetivos específicos e metas a serem atingidas em determinado espaço de tempo, os indicadores utilizados para avaliá-las, os recursos financeiros a elas associados, os cronogramas de repasse de recursos, entre outros elementos.

Ao término de um período especificado no contrato, o ministério supervisor da OS faria uma avaliação da sua execução, que no documento 
do MARE é chamada de avaliação de desempenho institucional. Esta

avaliação "significaria a análise e a avaliação do atingimento dos objetivos e metas pactuados, seu grau de realização e as causas e os efeitos dos desvios entre a programação e realização" (idem, 1996).

A partir dos resultados dessa avaliação, caso os objetivos e metas estabelecidos não fossem os pactuados, renegociar-se-ia as metas, objetivos, prazos e outras partes do contrato. Caso ocorresse a identificação, nessa avaliação ou a qualquer momento, de elementos que configurassem uso irregular dos recursos, suspensão do fornecimento do serviço ou outro fator relevante, o governo poderia intervir na OS, assumindo seu controle por no máximo 180 dias. Se os motivos que levassem à intervenção fossem confirmados, a OS seria desqualificada como tal. Caso contrário sua administração retornaria aos órgãos competentes.

Por fim, devem ser considerados outros elementos importantes característicos das OS quais sejam: voluntariedade, ou seja, as atuais fundações e autarquias somente se transformarão em OS se manifestarem interesse; regulamento próprio de compras; possibilidade de cessão de bens móveis e imóveis e pessoal da União para as OS. No caso de cessão de servidores federais, estes permanecerão submetidos ao Regime Jurídico Único, tendo sua remuneração custeada pela União.

\section{A proposta do MEC para a autonomia das IFES}

A idéia de autonomia das IFES é uma reivindicação antiga da comunidade acadêmica que encontrou abrigo no artigo 207 da Constituição federal de 1988 que garante a autonomia e a indissociabilidade do ensino, pesquisa e extensão nas universidades. Desde a promulgação da Constituição, vem sendo discutido o alcance desse artigo. Divergências jurídicas relativas a sua auto-aplicabilidade, à necessidade de lei complementar ou ordinária para a sua regulamentação; o seu alcance à questão das despesas com pessoal; o impacto da autonomia para as universidades particulares, e outros pontos permeiam a discussão sobre a autonomia universitária. ${ }^{1}$ Dados os objetivos deste trabalho, tais questões não serão abordadas, sendo enfocados apenas os aspectos da proposta de autonomia do MEC que afetam a administração das IFES.

A concepção de autonomia universitária, proposta pelo MEC, se baseia, entre outros elementos, na percepção da necessidade de que as universidades tenham autonomia administrativa, financeira e de gestão patrimonial, para que possam desempenhar melhor suas funções. Segundo um documento desse ministério:

"No caso do setor público há que se garantir, também, a autonomia administrativa, financeira e de gestão patrimonial, sem as quais as universidades se igualam a repartições públicas e ficam inteiramente 
manietadas pelo aparelho burocrático do Estado. Sem liberdade de estabelecer uma política de pessoal e remuneração, não só a liberdade acadêmica fica seriamente prejudicada, como as instituições, amarradas às normas do funcionalismo público, se tornam ineficientes. Da forma como está colocada hoje a questão, as injunções constitucionais para o serviço público em geral e para a elaboração do orçamento não fizeram as necessárias ressalvas para o caso das universidades federais, eliminando, na prática, a autonomia formalmente concedida no Artigo 207." (A política nacional para o ensino superior, 1996, 25)

Percebe-se, claramente, a semelhança entre o diagnóstico do MEC e o do MARE. No entanto, o MEC propõe uma solução mais conservadora do que a proposta de OS.

Para esse ministério, a autonomia deveria se dar sem que as universidades perdessem o caráter estatal que hoje as caracteriza. A manutenção desse caráter seria necessário, dado que as universidades fornecem um serviço público essencial, tornando imperativo assegurar a estabilidade e permanência das instituições. Pesa, também, para essa posição do MEC a forte percepção de que o ensino, em qualquer dos seus níveis, é uma obrigação do poder público e que a manutenção do caráter estatal das IFES seria a materialização dessa obrigação. Nesse sentido, a proposta cria a figura da entidade administrativa autônoma de regime especial denominada universidade pública.

O diagnóstico do MEC atenta para a necessidade de se aumentar a eficiência do gasto público, reconhecendo que há ineficiências administrativas nas universidades, e atribui isso ao fato de que o fluxo de recursos foi garantido sem qualquer vinculação com seu desempenho (Parecer sobre a proposta de criação de OS, 1996, 4). A vinculação de recursos para as universidades públicas ocorre através da folha de salários, pois, sendo os servidores enquadrados no Regime Jurídico Único e gozando de estabilidade e de garantias salariais, os recursos constitucionalmente vinculados à educação ${ }^{2}$ acabam sendo gastos com a manutenção dos servidores das universidades, despesa que não pode ser reduzida a não ser através de um arrocho salarial. Como solução, o MEC recomenda a elaboração de uma emenda constitucional e de regulamentação complementar que vincule recursos ao ensino superior sendo sua distribuição associada ao desempenho, ao mesmo tempo em que dê autonomia de gestão às universidades.

"Se o objetivo central é de modernizar o sistema, tornando-o mais eficiente, aumentando o atendimento que oferece à população, elevando a qualidade do ensino e desenvolvendo a pesquisa, a solução não é (...) mas substituir uma vinculação improdutiva por uma outra, que incentive a melhoria do desempenho, (idem, 1996, 4). 
A partir desse diagnóstico, a proposta do MEC cria o "Fundo para

a Manutenção e Desenvolvimento do Ensino Superior", composto de 75\% dos recursos federais já vinculados à rubrica educação, como forma de garantir um fluxo regular mínimo de recursos para as IFES. A autonomia financeira destas seria atingida à medida que esses recursos fossem repassados em duodécimos mensais como orçamento global.

A avaliação das características físicas de cada universidade e da consecução das metas desejadas em termos de melhoria do ensino, a ampliação de matrículas e o desenvolvimento de pesquisa seriam utilizados como elementos alimentadores de uma matriz de distribuição dos recursos alocados ao Fundo para a Manutenção e Desenvolvimento do Ensino Superior.

Na parte da gestão administrativa, financeira e patrimonial, a proposta do MEC elenca uma série de 19 autonomias a serem concedidas às IFES. Estas autonomias dizem respeito à organização interna, ao estabelecimento da política geral da instituição, à escolha de dirigentes, à admissão, promoção e demissão de docentes e técnicos administrativos, ao estabelecimento de planos de carreira e de remuneração, à criação de regulamento próprio para compras de bens e serviços, ao manejo dos recursos orçamentários providos pelo governo e da receita própria entre rubricas e categorias de despesa, entre outras.

O acompanhamento das universidades seria feito pelo MEC, através da criação de uma sistemática de avaliação do desempenho das universidades que levasse em conta o projeto de instituição desenhado pela comunidade acadêmica de cada universidade. Esse acompanhamento informaria o processo de credenciamento e recredenciamento das instituições. Inicialmente, as universidades existentes seriam avaliadas e as que preenchessem os requisitos mínimos exigidos seriam credenciadas como tais, tendo direito às autonomias acima explicitadas. As IFES que não cumprissem os requisitos necessários seriam denominadas centros universitários, possuindo uma autonomia limitada. Periodicamente, as universidades deveriam se recredenciar, através de nova avaliação, como forma de manter as autonomias concedidas. Os requisitos para o credenciamento estão definidos no projeto de lei da autonomia e contemplam um amplo espectro de variáveis ligadas ao desempenho acadêmico das instituições.

\section{Semelhanças e divergências entre as propostas}

Nesta seção, procura-se fazer uma comparação dos dois projetos acima apresentados. O objetivo é identificar os elementos comuns e as divergências entre as duas concepções de como deveria se dar o funcionamento das IFES em um contexto de reforma do Estado. 
Procurando inicialmente observar os pontos comuns, verifica-se que ambas as propostas partem de um diagnóstico semelhante sobre os elementos que caracterizam a administração pública atual. Apontam o modelo de administração burocrático como inadequado para o funcionamento da administração indireta, ressaltando as dificuldades administrativas dele decorrentes e suas implicações para a qualidade do serviço prestado e para a eficiência das instituições a ele sujeitas.

Algumas divergências surgem, quando se trata da identificação da origem da imposição desse modelo às entidades da administração indireta. O diagnóstico do MARE aponta para uma conjugação de fatores ocorridos no período do Congresso Constituinte, ressaltando a identificação da crise do Estado com o processo de descentralização e com os desmandos observados nessa esfera da administração. Já o diagnóstico do MEC afirma que a origem da imposição dos controles burocráticos decorreu da intolerância do núcleo estratégico do Estado em admitir uma administração menos centralizada e mais flexível. Essa intolerância decorreria da incapacidade do Estado burocrático centralizador de estabelecer novos mecanismos de controle financeiro e da qualidade de serviços, diferentes dos tradicionais (idem, 1996, p.1). Embora essa questão esteja presente no diagnóstico do MARE, nele não assume a mesma importância.

Um segundo ponto de concordância se refere ao conteúdo das soluções apresentadas. As duas propostas centram atenção na necessidade de se conceder maior autonomia às entidades da administração indireta, substituindo o modelo administrativo vigente por um novo modelo, mais flexível e mais compromissado com o desempenho e com a qualidade dos serviços prestados.

Outra concordância entre as propostas pode ser encontrada na definição do papel do Estado com relação às IFES. Nas duas concepções, este deve agir no sentido de controlar as instituições através do desempenho, com a substituição dos controles formais por controles que avaliem os resultados obtidos em função dos recursos disponíveis.

Apesar dessas semelhanças, quando se compara as soluções propostas pelo MEC e pelo MARE para a administração das IFES, surgem, uma série de divergências que procuraremos explorar a seguir.

A principal divergência diz respeito à natureza das entidades da administração indireta. Enquanto o Plano Diretor da Reforma do Aparelho do Estado postula que as universidades devem ser transformadas em OS, adotando uma forma definida pelo direito privado e assumindo um caráter público não-estatal, a proposta do MEC mantém essas instituições dentro do aparelho do Estado.

Essa é uma diferença significativa, uma vez que a manutenção das IFES como entidades de direito público cria uma série de obrigações e direitos que não existiriam caso seu formato jurídico fosse de OS. O vínculo 
com a administração direta seria muito mais forte, os servidores seriam estatutários, ainda que com estatuto diferenciado, seu orçamento seria agregado ao do MEC e seria votado pelo Congresso. As possibilidades de adoção de um regime de compras diferenciado do vigente para a administração direta seriam menores, dada a existência de instrumentos legais reguladores. As autonomias concedidas deveriam ser muito bem detalhadas, para evitar problemas com os sistemas de controle interno e externo aos quais essas instituições permaneceriam submetidas. ${ }^{3}$ Por outro lado, a manutenção das IFES dentro do aparelho do Estado representaria uma mudança menos radical do que a proposta de sua transformação em OS, o que certamente facilitaria a aceitação das mudanças propostas e o controle por resultado nos moldes propostos pelo MEC.

Um ponto a ser considerado é o tema da manutenção do interesse público na definição dos objetivos e na orientação das IFES. Embora essa questão seja contemplada no projeto de OS, há críticas relativas à atual capacidade dos organismos da sociedade civil em assumir uma tarefa complexa como a administração de organizações que chegam a ter 13 mil funcionários (A política nacional para o ensino superior, 1996, 35). Caso se assuma que essa crítica é válida, a permanência dessas instituições dentro do aparelho do Estado pode ser uma medida de segurança quanto à prevalência do interesse público na sua orientação.

Outra divergência que pode ser apontada está relacionada à organicidade das propostas. A proposta do MEC desce muito mais a detalhes do que a proposta do MARE, chegando a propor a criação de um Sistema Federal de Ensino Superior, dirigido por um conselho cuja composição incluiria todos os reitores e diretores de IFES. Esse conselho deveria constituir-se em um fórum de uniformização de alguns aspectos da administração universitária, além de servir como interlocutor entre as IFES e o MEC, coordenador dos processos de auto-avaliação, e de locus de discussão de temas de interesse geral e comum (Anteprojeto das leis sobre autonomia das universidades federais, 1996, p.6).

O MARE, por outro lado, trata a questão das OS de uma forma "particularista", não abordando a articulação dessas organizações dentro de uma visão de coordenação das ações do governo. O contrato de gestão permite, no máximo, a coordenação vertical entre o governo e as organizações. Não há, ao contrário do projeto do MEC, nenhum instrumento que procure garantir alguma coordenação horizontal entre as OS.

A diferença entre as duas propostas pode estar ligada ao fato de a proposta do MARE não ser exclusiva para as IFES, devendo ser aplicada às mais diversas organizações públicas, atuando em diferentes áreas da administração indireta. Essa abrangência tornou o projeto de OS necessariamente mais genérico do que uma proposta específica para um grupo de instituições, como é a proposta formulada pelo MEC. 
Mais uma divergência entre as propostas pode ser encontrada no que se refere à organização interna das IFES. Enquanto a proposta de criação das OS obriga-as a instituírem um conselho de administração ou conselho curador com uma composição previamente determinada, a proposta de autonomia não faz nenhuma referência às mudanças na atual organização das instituições de ensino superior, deixando a cargo das universidades a definição dos critérios de escolha de seus dirigentes, respeitadas as determinações legais. Essa questão é relevante, à medida que a comunidade acadêmica forma um corpo que desenvolve e mantém relações políticas internas, e desde o início dos anos 80 as instituições universitárias tem gradualmente aumentado sua autonomia na escolha de seus dirigentes. A possibilidade de que a direção das IFES passe para um conselho com grande participação do governo ou de elementos estranhos ao meio universitário suscita críticas e resistências acentuadas. Na visão do MEC,

“(...) um problema crucial, que sempre interferiu na gestão adequada das universidades públicas, foi a tentativa permanente de fazer valer critérios político-partidários clientelistas externos à universidade na escolha dos dirigentes. Apesar dos defeitos que [acabou apresentado] (e que estão agora sendo corrigidos), o movimento pela eleição direta dos reitores constituiu uma reação de certa forma positiva a este tipo de ingerência, que ainda não foi de todo eliminada." "Considerando o que uma universidade (...) representa como cacife político (...) não haverá como evitar uma disputa política que levará ao loteamento das indicações para o conselho(...)". "Essa é uma das razões pelas quais o conselho curador poderá representar a destruição da autonomia da Universidade, transformando seu órgão máximo de decisão num objeto de disputa na arena da política partidária" (Parecer sobre a proposta de criação de OS, 1996, 2-3).

A posição do MEC de defesa da autonomia da escolha de seus dirigentes não é isenta de críticas, uma vez que ela pode facilmente resvalar para a defesa de concepções e orientações de interesse exclusivo da comunidade acadêmica, sem nenhuma relação com a sociedade que a envolve e a suporta. Há de se imaginar novas formas de escolha dos dirigentes das IFES que sejam capazes de impedir o uso político-partidário dessas instituições bem como a apropriação de sua direção por grupos corporativos.

Uma outra divergência diz respeito à questão do financiamento. A proposta de OS não dá nenhuma garantia da manutenção do fluxo de recursos para as IFES, ficando todo o repasse de verbas sujeito às negociações do contrato de gestão. A proposta do MEC, ao contrário, parte da 
idéia de vinculação de recursos para o conjunto das universidades. Em

princípio, esta proposta parece mais vantajosa para as IFES, que resistem fortemente a ter de depender de repasses voluntários de recursos federais. Esta resistência se baseia na história de descontinuidade que caracteriza a administração pública brasileira, manifesta em obras inacabadas e iniciativas abortadas a cada mudança de governo. Sob esse aspecto, a resistência das IFES é perfeitamente compreensível à medida que nada pode garantir que essas práticas não pertençam mais ao cotidiano da administração, ainda mais num contexto de persistente desequilíbrio fiscal.

Apesar da visibilidade e do apelo do tema, a divergência em torno da vinculação de recursos deve ser avaliada em termos do seu real significado em termos financeiros para as IFES. No projeto das OS, está definido que os funcionários públicos cedidos a essas organizações os serão às custas da União, sendo mantida sua vinculação estatutária atual. Se, como afirma o documento do MEC, $90 \%$ da despesa das IFES é exatamente com o pagamento de pessoal (A política nacional para o ensino superior, 1996, 34), a conclusão lógica é que, caso as universidades se transformem em OS, terão no mínimo $90 \%$ de sua despesa garantida pelo governo. Conclui-se, portanto, que a discussão sobre vinculação de recursos é relevante para decidir apenas $10 \%$ do orçamento das universidades, uma vez que os recursos de pessoal serão garantidos qualquer que seja a estrutura adotada pelas IFES.

\section{Análise das propostas e suas insuficiências no contexto atual}

Para se analisar a adequação das duas propostas de reforma apresentadas, deve-se levar em conta a "aderência" destas com relação à realidade concreta em que estão inseridas as IFES. Nesta seção procura-se apresentar alguns problemas administrativos dessas instituições e a adequação das duas propostas para resolvê-los.

Em primeiro lugar, pode-se considerar que uma das principais questões que afetam a administração das universidades é o processo de escolha de seus dirigentes. A direção administrativa nessas organizações é concentrada em uma pessoa, seja reitor ou diretor de unidade. $\mathrm{O}$ fato desses dirigentes serem escolhidos através de um processo eletivo competitivo, no qual participam todos os membros da comunidade universitária, ${ }^{4}$ faz com que apenas por sorte o dirigente escolhido tenha um mínimo de capacidade gerencial. ${ }^{5}$ Esse problema pode ser minorado, mas não eliminado, com a atribuição de maior importância ao corpo docente na escolha dos dirigentes, especialmente em organizações onde haja um grande número de docentes e, conseqüentemente, de eleitores. ${ }^{6}$ A legislação atual, atenta a esse fato, exigiu que o corpo docente tenha um peso mínimo de $70 \%$ no processo de escolha dos dirigentes das IFES. 
Uma das consequiências desse processo de escolha dos dirigentes é que ele tende a gerar uma direção que não tem interesse em arcar com o ônus e os custos do gerenciamento, uma vez que decisões administrativas que prejudicam pessoas ou grupos afetam diretamente sua base de apoio. Como resultado, tem-se uma administração que se caracteriza por evitar enfrentar os problemas cuja solução imponha custos à "comunidade universitária" e que procura antes de tudo manter o status quo vigente.

Um segundo problema é o baixo nível de autonomia das administrações universitárias, em relação à administração de pessoal e à questão orçamentária-financeira. Essa falta de autonomia gera um desestímulo à inovação e à tendência de transferir os problemas para o nível hierarquicamente superior. Os problemas existentes são, com facilidade e com grande freqüência, traduzidos em termos de falta de recursos financeiros e humanos, e a responsabilidade por essa falta é atribuída aos Ministérios da Educação e do Desporto e da Administração Federal e Reforma do Estado.

Um terceiro problema das administrações das IFES é a incapacidade gerencial do seu corpo técnico-administrativo. Esta incapacidade, gerada por fatores como a pouca autonomia para a movimentação de recursos, a existência de poucos quadros qualificados e a concentração das decisões administrativas no corpo docente, gerou uma tendência ao que pode ser chamado de administração por inércia. Ou seja, faz-se hoje o que foi feito ontem e assim por diante.

Outro problema que pode ser identificado é a inexistência, dentro das IFES, de instâncias de negociação do orçamento e de definição de prioridades de atuação. Isso é decorrente dos fatores acima expostos: falta de autonomia orçamentária e financeira, falta de interesse das administrações em debater um tema naturalmente polêmico, incapacidade técnica e administrativa de identificar os custos de manutenção dessas instituições e de planejar as ações futuras, falta de informações e condições necessárias para a elaboração de um orçamento que represente os objetivos e metas da instituição. Como consequiência, não se tem transparência sobre os projetos a serem implementados e abre-se espaço para a atuação política dos dirigentes na alocação dos recursos.

Dados todos esses problemas, seria interessante que fosse considerada a forma como as propostas do MARE e do MEC os encaram. A proposta do MARE, caso aplicada às IFES, alteraria a estrutura de direção das universidades. Hoje a direção é exercida pelo reitor e seus auxiliares, os pró-reitores, sob a supervisão dos conselhos universitários, de composição variada, mas, normalmente, contando basicamente com representação das unidades ${ }^{7}$ da universidade, do corpo docente, do corpo discente e dos funcionários técnico-administrativos, com predomínio numérico do corpo docente. Na proposta das OS, haveria um conselho de 
administração ou curador que assumiria todas as funções dos conselhos universitários e mais algumas atribuições do reitor, ${ }^{8}$ sendo que a sua própria figura deixaria de existir, uma vez que o conselho assumiria a competência de nomear e fiscalizar os membros da diretoria, que exerceriam as atividades administrativas.

Como já foi colocado, essa alteração encontra grande resistência entre a comunidade acadêmica. $\mathrm{O}$ formato utilizado suscita dúvidas também à medida que ele não considera a existência, dentro das universidades, das unidades que possuem alguma autonomia administrativa, além de grande independência na escolha de seus dirigentes. Como seriam estruturadas as relações entre os diretores de unidades e o conselho de administração ou curador? Caso os critérios de escolha dos membros do conselho e dos diretores fossem diferentes, mantendo-se a escolha direta para os últimos, estes poderiam constituir focos de resistência a decisões do conselho, já que teriam maior legitimidade. Seria o caso de instituírem-se conselhos para substituir os diretores? A relação entre a direção da organização e suas unidades constituintes não é considerada no projeto de OS e, embora seja uma especificidade das universidades, merece maior reflexão.

A proposta do MEC não altera em nada a atual estrutura de direção das IFES. Esta posição, embora encontre maior suporte político, não toca em alguns dos problemas anteriormente apontados. A atual estrutura de direção das universidades permite que interesses não compatíveis com uma gerência eficiente e eficaz influenciem a tomada de decisão. Ao mesmo tempo, concentra as decisões administrativas na reitoria, e dá pouca autonomia para os diretores de unidades.

Com relação ao aumento da autonomia, as duas propostas apontam claramente na direção de aumentar a flexibilidade administrativa das IFES. Com relação às formas como a concessão da autonomia viabilizaria uma maior eficiência, a proposta do MEC aponta que a concessão de autonomia orçamentária e financeira induzirá os reitores e diretores a assumirem uma postura gerencial de busca da eficiência. Embora esta seja uma hipótese provável, não é possível garantir que isso ocorra. $\mathrm{O}$ mesmo pressuposto está incorporado à proposta do MARE, embora, nesse caso, a condição de organização de direito privado aumente a responsabilidade dos dirigentes.

Outro ponto a ser considerado é a resistência que as propostas de autonomia e de OS encontram dentro das IFES. Se as condições atuais fossem mantidas ou caso a autonomia proposta pelo MEC seja concedida apenas em parte, não haveria a necessidade de internalização de questões que hoje são tratadas fora da universidade, diretamente com o MEC e o MARE. ${ }^{9} \mathrm{O}$ custo dessa internalização pode ser grande, caso as divergências dentro do corpo docente ou entre este e o corpo discente e/ou com os funcionários técnico-administrativos sejam muito acentuadas. 
Com relação à falta de capacidade técnica para a gerência, nenhuma das duas propostas apresentadas se preocupa com esta questão. Sabese que a qualificação de recursos humanos é uma tarefa dispendiosa e demorada, mas fundamental para o sucesso tanto do projeto das OS quanto do projeto de concessão de autonomia. No entanto, nenhuma das propostas se preocupa com a incapacidade das IFES em gerar e utilizar informações básicas para a implantação de uma administração mais eficiente e flexível. ${ }^{10}$ Num contexto de falta de pessoal qualificado, de carência de know how administrativo, de falta de informações gerenciais e também de motivação, a implantação da autonomia ou a transformação das IFES em OS de um momento para outro poderia gerar sérios problemas operacionais, inviabilizando tanto a implantação do contrato de gestão proposto pelo MARE, quanto o desenho de um projeto para a instituição que subsidiaria sua avaliação, como proposto pelo MEC.

A mesma crítica pode ser feita com relação à questão orçamentária nas IFES. A elaboração de um orçamento transparente, capaz de refletir os objetivos da instituição requer uma base técnica e a existência de espaços institucionais de discussão do orçamento, condições ausentes atualmente na grande maioria das IFES. Considerando a proposta de autonomia do MEC uma incógnita, até que ponto — os atuais conselhos universitários poderiam assumir essa função. No caso da proposta de OS, o conselho administrativo ou curador, apesar de ter a incumbência legal de aprovar a proposta de orçamento, não parece possuir, dada a sua composição, legitimidade interna para encaminhar a discussão do orçamento das IFES.

Pode-se observar, portanto, que ambas as propostas deixam, em aberto, algumas questões importantes para a administração das universidades. Isso pode ser creditado em grande parte à diversidade de instituições que elas procuraram englobar. Com relação à proposta do MARE, já foi mencionado que a origem do seu pouco detalhamento é a própria concepção do projeto de OS que, ao ser elaborado para abranger toda a administração indireta teve, como contrapartida, de se limitar a estabelecer critérios gerais para a criação e funcionamento dessas organizações.

Pelo lado da proposta de autonomia das IFES elaborado pelo MEC, pode-se afirmar que embora esta tenha sido feita em condições muito mais propícias para tratar de temas específicos dessas instituições, também é incompleta. Isso pode ser justificado pela necessidade de acomodar, no âmbito da proposta, situações concretas muito diversas encontradas no universo das 52 instituições federais de ensino superior. Não se pode comparar universidades como as do Rio de Janeiro e de Minas Gerais com as Universidade de Alagoas e Universidade Rural de Pernambuco. Isso sem mencionar as faculdades e escolas isoladas ou as pequenas fundações universitárias como as de São João del-Rei e do Amapá. Fica patente a dificuldade de se estabelecerem regras que acomodem todas essas instituições. 


\section{Sugestões e conclusões}

A partir do que foi apresentado, pode-se tentar oferecer algumas sugestões relativas ao processo de concessão de maior autonomia e flexibilidade para as instituições federais de ensino superior, seja no âmbito da proposta de OS do MARE, seja na esfera do projeto de autonomia elaborado pelo MEC.

Uma sugestão está relacionada à questão da estrutura administrativa das IFES. A atual estrutura concentra num órgão as funções de representação política da instituição e as funções administrativas. Talvez seja melhor pensar numa organização que separe as duas funções, tendo um conselho que defina os fins, objetivos e metas da instituição, incorporando assim funções políticas, e uma administração profissionalizada que procure implementar as decisões do conselho. Essa proposta se assemelha ao desenho institucional proposto pelo MARE, deixando, em aberto, a composição desse conselho.

Complementarmente à essa proposta existe a necessidade de profissionalização da carreira de administrador dentro das IFES. A visão do MEC de que as universidades são organizações com muitas peculiaridades é correta, e isso torna ainda mais necessário que seja feito um esforço intenso no sentido da formação de administradores de universidades, capazes de agregar as demandas específicas dessas instituições a modelos de administração mais eficientes. Isso exigiria um processo de treinamento e reciclagem dos funcionários administrativos e a valorização dessa carreira dentro das IFES, inclusive com a concessão de maior autonomia decisória para os funcionários que ocupem cargos de direção na estrutura administrativa.

Dadas as deficiências na capacidade administrativa apontadas no texto, seria conveniente que a concessão de maiores autonomias, através de quaisquer das modalidades propostas, seja feita de forma gradual. Isso é especialmente verdadeiro com relação à autonomia na gestão do orçamento e das finanças. Em entrevista ao autor, técnicos do MEC afirmaram que não mais do que aproximadamente 5\% das IFES teriam atualmente condições de elaborar um orçamento realista, que não fosse apenas uma repetição de orçamentos passados. Nessas condições, e dada a diversidade das capacidades institucionais das IFES, a concessão da autonomia ou a transformação em OS é um risco, e a concessão gradual da autonomia pode ser uma forma de minimizá-lo. Seria interessante também que fossem criados ou revitalizados espaços institucionais onde fosse possível estabelecer uma discussão interna sobre o orçamento.

Outro ponto a ser considerado para o aumento da eficiência e eficácia da administração das universidades é a autonomia das unidades que a compõem. Essa questão, ausente das duas propostas, é relevante, porque é nas unidades que se dá o exercício profissional da maioria dos servidores 
das universidades, onde se encontram todos os alunos e onde são realizadas

as pesquisas. $\mathrm{O}$ modelo atual dá às unidades uma autonomia mínima, o que associado à forma de escolha de seus dirigentes não gera incentivos para que se busque maior eficiência. $\mathrm{O}$ aumento da flexibilidade administrativa e a mudança nos critérios de escolha dos diretores dessas unidades poderá redundar em uma melhoria da eficiência das IFES, através de um atendimento mais rápido das demandas colocadas pelas áreas de ensino e pesquisa. Seria conveniente também que fosse adotada uma sistemática de controle administrativo dessas unidades, por parte das reitorias, que estimulasse a busca de maior eficiência na sua atuação.

Viu-se que as propostas apresentadas pelo MARE e pelo MEC partiram do mesmo diagnóstico, e, conseqüentemente apontaram para a mesma solução, ou seja, a liberação das IFES do modelo de administração burocrático típico da administração direta.

Esse diagnóstico comum, embora leve a modelos diferenciados de concessão de autonomia, também possibilita que as propostas sejam vistas antes como modelos complementares do que como modelos excludentes de organização das IFES.

Conquanto as dificuldades de implementação do modelo de OS para grandes universidades sejam significativas, sua aplicação às pequenas universidades, às faculdades e escolas isoladas não parece suscitar problemas de grande monta. Estas instituições ${ }^{11}$ normalmente se concentram em atividades docentes, tendo uma atividade de pesquisa incipiente. Essa característica, associada à maior homogeneidade de interesses dentro da instituição, dado o seu menor tamanho e áreas de atuação, as assemelham às instituições privadas de ensino, a partir do que pode-se imaginar que a forma de administração dessas possa ser utilizada nas IFES citadas. A proposta do MEC reconhece essa diferenciação entre as IFES e afirma que essas instituições merecem um tratamento separado das grandes universidades, recomendando que as autonomias a serem concedidas às mesmas seja menor do que as concedidas às grandes IFES.

Por outro lado, o modelo de OS trata de forma simples ou mesmo desconsidera diversos elementos presentes na complexa realidade das grandes universidades. Para essas instituições parece ser mais viável o modelo de autonomia proposto pelo MEC que propõe um aperfeiçoamento de sua estrutura e funcionamento.

Deve-se observar ainda que as duas propostas não consideram algumas características das IFES que são importantes para que a concessão da autonomia gere os resultados esperados, aumentando a eficiência e a eficácia dessas instituições. Essa talvez seja a principal deficiência das duas, o que implica a conveniência de que sua implantação seja feita com cuidado, se possível de forma experimental em algumas instituições, para que os problemas que surgirem e suas soluções 
sirvam de modelo para as outras IFES. Essa estratégia parece ser a mais segura para se proceder às mudanças institucionais de grande porte, à medida que facilita a manutenção das atividades cotidianas da organização durante o processo de mudança. Essa consideração deve ser a balizadora dos processos de implantação das reformas das estruturas da administração indireta, quaisquer que sejam elas. 
1 O conceito de instituição federal de ensino superior engloba universidades, faculdades isoladas e centros de educação tecnológica mantidos pela União. A discussão da autonomia está mais centrada nas universidades, embora pleiteie-se sua extensão parcial aos outros dois tipos de instituições de ensino superior. Por isso utilizaremos também a expressão autonomia universitária para designar a autonomia de todas as IFES.

$218 \%$ da receita de impostos, descontados os valores constitucionalmente pertencentes a estados e municípios.

3 Textos de divulgação do MARE sobre o projeto de OS também colocam sob o alcance dos órgãos de controle interno e externo do governo federal (Jornal do Servidor, jan.1997, p.4). Isso significa que caso não haja um entendimento muito claro entre o MARE, a Secretaria Federal de Controle e o Tribunal de Contas da União, a respeito do alcance das autonomias dessas organizações e quais as suas implicações práticas, poderão surgir grandes dificuldades jurídicas cujos efeitos poderiam levar até mesmo à inviabilização do modelo proposto.

4 A "comunidade universitária" é composta de alunos, professores e funcionários. A comunidade acadêmica é composta pelos corpos docente e discente.

5 O processo eleitoral competitivo, especialmente quando se dá entre grupos de interesses heterogêneos, exige dos postulantes ao cargo em disputa a capacidade de adotar políticas de compromisso com os diversos grupos. Esta capacidade, fundamental para se ganhar esse tipo de eleição, não implica absoluto na existência de aptidão gerencial.

6 Está-se considerando que em grupos menores haja maior facilidade de se construir um consenso sobre a orientação a ser dada à instituição.

7 Essas unidades são as faculdades e centros que compõem as universidades.

8 Considera-se aqui que a determinação constante do projeto de lei de criação das OS de que os conselhos de administração ou curadores devem "escolher, designar e dispensar os membros da diretoria", significaria escolher os ocupantes dos atuais cargos de próreitores.

9 Muitas vezes a identificação de um problema com uma agência externa à universidade é utilizada como elemento de mobilização da "comunidade universitária", servindo como fator de superação de divergências internas à instituição.

${ }^{10} \mathrm{Na}$ realidade, a proposta do MARE contempla um tipo específico de contrato de gestão que seria aplicado a organizações ainda não desenvolvidas institucionalmente para trabalhar com um elevado grau de autonomia em relação ao governo. Essa proposta não parece satisfatória, dado as precárias condições em que se encontram as administrações universitárias.

${ }^{11}$ Existem hoje sete faculdades ou escolas isoladas entre as 52 IFES. Das 45 IFES restantes, um grande número é de pequenas universidades. 


\section{Referências bibliográficas}

Associação Nacional dos Dirigentes das Instituições Federais de Ensino Superior. Autonomia Universitária. Brasília, 1994.

. Lei Orgânica das universidades: proposta de um anteprojeto de lei. João Pessoa, PB, outubro de 1996, 44 p.

Ministério da Educação e do Desporto. Ante-projeto de lei sobre autonomia das universidades federais, Secretaria de Política Educacional. Brasília, julho de 1996, 14 p.

Ministério da Educação e do Desporto. A política nacional para o ensino superior. Secretaria de Política Educacional. Brasília, setembro de 1996, 42 p.

Ministério da Educação e do Desporto. A avaliação do ensino superior. Secretaria de Política Educacional. Brasília, setembro de 1996, 9 p.

Ministério da Educação e do Desporto. Parecer sobre a proposta de criação de Organizações Sociais. Secretaria de Política Educacional. Brasília, 1996, 5 p.

Ministério da Administração Federal e Reforma do Estado. Projeto Organizações Sociais. Secretaria da Reforma do Estado, Brasília, 1996.

Presidência da República. Plano Diretor da Reforma do Aparelho do Estado. Câmara da Reforma do Estado, Brasília, 1995, 86 p.

Bresser Pereira, Luiz C. Da administração pública burocrática à gerencial. Revista do Serviço Público. Brasília, v.120, n.1, p. 7-37, jan-abr 1996.

Ferrarezi, Elisabete R. et al. Flexibilização da administração indireta: desafios da reforma. Brasília, ENAP, 1996. Trabalho apresentado no Curso de Formação de Especialista em Política Pública e Gestão Governamental. Ciclo de Atividades Aplicadas.

Jornal do Servidor. Organizações sociais garantem servidores estatutários. Ano 2, n.11, janeiro de 1997, p.4. 
Resumo

Resúmen

Abstract

Organizações sociais, instituições federais de ensino superior e autonomia universitária

Eduardo da Silva Pereira

O artigo contrapõe modelos alternativos de organização das Instituições Federais de Ensino Superior (IFES) propostos pelo Ministério da Administração e Reforma do Estado (MARE), no âmbito do Programa de Reforma do Estado, e pelo Ministério da Educação e do Desporto (MEC). Procura também avaliar de que forma as soluções propostas enfrentam alguns problemas característicos dessas instituições, levantando questões sobre a viabilidade desses modelos. Apresenta, ainda, algumas sugestões para a abordagem dos problemas apontados.

Organizaciones sociales, instituciones federales de enseñanza superior y autonomia universitaria

\section{Eduardo da Silva Pereira}

El artículo compara modelos alternativos de organización de las Instituciones Federales de Enseñanza Superior (IFES) propuestos por el Ministerio de la Administración y Reforma del Estado (MARE), en el ámbito del Programa de Reforma del Estado, y por el Ministerio de Educación y de Desporte (MEC). El artículo busca evaluar de qué forma las soluciones propuestas afrontan algunos problemas característicos de tales instituciones, tratando de cuestiones sobre la viabilidad de tales modelos. Aún, él apresenta algunas sugestiones para el abordage de los problemas presentados.

\section{Social organization, federal institutions of higher education and university autonomy \\ Eduardo da Silva Pereira}

The article oppose alternative models of organization for the Federal Universities suggested by the Ministry of Federal Administration and State Reform, in the scope of State Reform Program, and by the Ministry of Education and Sports. Also try to evaluate how the solutions offered broach some specifics problems of these institutions, pointing out questions about their viability. Still show sugestions to tackle some pointed problems. 